\title{
Sustainable Withdrawal Rates of Retirees: Is the Recent Economic Crisis A Cause for Concern?
}

\author{
Swarn Chatterjee (Corresponding author) \\ University of Georgia \\ 205, Dawson Hall, Athens, GA 30602, USA \\ Tel: 1-706-542-4722 E-mail: swarn@uga.edu \\ Lance Palmer \\ University of Georgia \\ 205, Dawson Hall, Athens, GA 30602, USA \\ Tel: 1-706-542-4916 E-mail: lpalmer@uga.edu \\ Joseph Goetz \\ University of Georgia \\ 205, Dawson Hall, Athens, GA 30602, USA \\ Tel: 1-706-542-2066 E-mail: goetz@uga.edu
}

\begin{abstract}
A sustainable standard of living at retirement is an issue of great importance for most retirees, and is certainly a major consideration in the allocation of client portfolios for private wealth managers. This study uses historical returns and incorporates boot strapping techniques to determine the safe withdrawal rates for retiring households between 1990 and 2005. This time period is chosen because it captures the market shock at the beginning of this millennium as well as the global economic downturn of 2007-2008. The results of this study indicate that while $3 \%$ and $4 \%$ withdrawal rates are sustainable in most cases, a $5 \%$ withdrawal rate is not sustainable for recent retirees given the conventional 60/40 asset allocation strategy.
\end{abstract}

Keywords: Asset allocation, Withdrawal strategies, Portfolio management

\section{Introduction}

As clients approach their retirement, one of the primary issues that concern their financial planners is the rate of withdrawal that can be applied to the initial value of clients' retirement portfolios, so that the periodic withdrawals from these portfolios can be sustained through the lifetime of their clients. This is an important decision that financial planners must help their clients make because if the withdrawal rate is too high, then the clients must lower their level of living later in retirement, or run out of money during their lifetime. Conversely, if the withdrawal rate is too low then the clients have unnecessarily reduced their standard of living over their lifespan. This issue of sustainable withdrawal rates has been addressed in a number of previous studies (Ameriks, Veres, \& Warshawsky, 2001; Bengen, 1994, 1996, 1997; Cooley, Hubbard, \& Walz, 1999, 2003). According to Ameriks et al., the amount (either in dollar terms or as a percentage) that can be withdrawn without exhausting a client's portfolio is a key component of dependable retirement planning advice that financial planners need to provide for their retiring clients. Although most financial planners have access to historical return data and simulation software programs that project future market returns, planners have neither the exact returns markets will generate in the future, nor the knowledge of exact inflation rates that will occur during the lifetime of their clients. Financial planners also have their own inherent cognitive biases (Laing, 2010). Thus, further data is required to form best practices for financial planners and wealth managers in their work to manage their clients' longevity risk and investment portfolios.

This paper explores the issue of sustainable withdrawal rates by examining several diversification strategies that can make the withdrawal process more stable and reliable over the lifetime of retirees. We extend the existing literature by including market returns through 2008. This period is particularly significant because it includes two recent financial market downturns - 2002 and 2008, and a brief period of significant market recovery 2003-2007. We apply a boot strapping technique to simulate separate future returns for stocks, bonds, and inflation rates instead of using a simplistic model comprising of mean portfolio return and standard deviation. The remaining components of this paper are comprised of a detailed review of literature, followed by a discussion of methods, results, and finally a brief discussion of our findings.

\section{Literature Review}

Extant research suggests that clients can sustain annual withdrawals of around four to six percent of their initial retirement portfolio, without prematurely running out of money during their lifetime (Ameriks, et al., 2001, Bengen, 1994, Cooley, Hubbard, \& Walz, 1998, 2003; Guyton, 2004; Guyton \& Klinger, 2006; Ho, Milevsky, \& Robinson, 
1994; Pye, 1999, 2000). Other studies further emphasize that a 4 percent withdrawal rate is sustainable when investors use a 60 percent allocation in stocks and 40 percent allocation in bonds (Polyak, 2005; Whitaker, 2005). When using monthly returns from 1930 through 2001, Ervin, Filer and Smolira (2004) find that a portfolio comprising of 60 percent domestic equity and 40 percent intermediate bonds can sustain withdrawal rates of 6 to 7 percent over a retirement span of 30 years. Cooley et al. (1999) study finds that a portfolio with 75 percent allocated in stocks and the rest allocated in corporate bonds can sustain 4 to 5 percent inflation adjusted annual withdrawals. In a follow up study (Cooley et al., 2003) the researchers find that when using market data up to 2001, some international diversification ( 25 percent) helps when the retirement pay out period is long. Hughen, Laatsch and Klein (2002) use historical data through 2000 to find that 100 percent allocation in equities can sustain annual withdrawal rates of up to 7 percent over 30 years of retirement life for a retiree.

Stout (2008) contends that a gradually increasing withdrawal rate from an optimized portfolio can help retirees sustain higher withdrawal rates and support an improved retirement lifestyle. Using a stochastic analysis approach (instead of the more popular Monte Carlo simulation) to project future returns, Milevsky and Robinson (2005) find that retirees who withdraw about two to three percent annually have much lower risk of running out of money during their lifetime, as compared to those who maintain a withdrawal rate of 4 percent Furthermore, Milevsky and Robinson suggest that individuals who withdraw five percent of their portfolio or higher have a high probability of running out of money during their lifetime.

Monte Carlo technique has been used in business and financial forecasting by several researchers and analysts over the past half century. Hertz (1964) has been among the first to suggest the application of Monte Carlo analysis for business forecasting applications. However, Lewellen and Long (1972) caution that Monte Carlo simulation may not always be accurate and analysts can arrive at the same conclusion by using simple point estimates. Philippatos (1973) suggests that dynamic optimization techniques can be used for forecasting and that Monte Carlo simulation must be used only as a last resort. According to the Pilippatos study, analysts need to first explore other simulation techniques such as sensitivity analysis, strategic or 'what if' analysis, and interactive or decision tree analysis before they apply the Monte Carlo analysis. Myers (1976) argues that Monte Carlo simulation works best in situations where analysts have no idea how a variable is going behave in the future. Rubinstein (1981) further extends Myers' suggestion by setting up a list of criteria appropriate for Monte Carlo simulation analysis. According to Rubinstein, Monte Carlo simulation can be used when it is either impossible or very expensive to obtain future data, or when the analysis is too complex and when it is difficult to obtain a solution using other methods. Rees and Sutcliffe (1993) also find that Monte Carlo simulation is useful when nothing else works. Evensky (2001) finds that Monte Carlo simulation is useful for explaining to people the uncertainty of risk, but he also observes that Monte Carlo simulation increases assumptions significantly since it uses guesswork to arrive at the estimates. Nawrocki (2001) finds that application of Monte Carlo analysis may lead to incorrect decisions at times. According to Nawrocki, one of the biggest short comings of this form of analysis is that it is very difficult to replicate the real world situations exactly using Monte Carlo simulation techniques. Additionally, the conditions for Monte Carlo analysis require that there is no serial correlation between successive periods of returns and if correlations exist they must be linear. If these conditions are not met then the analysis might generate incorrect results.

There have been a few basic methods that have been applied in previous studies for estimating future returns to determine a sustainable withdrawal rate over the lifetime of individuals. The earliest studies used a rolling period return or an overlapping return as a proxy for future market returns (Bengen, 1994; Hughen, et al., 2002); the second method simulates future returns using different iterations and probabilities, typically a Monte Carlo simulation, or a stochastic optimization using Monte Carlo (Pye, 1999; Stout, 2008), and a stochastic analysis without Monte Carlo (Milevsky \& Robinson, 2005). In a recent study by Lemoine, Cordell and Gustafson (2010), the authors use Monte Carlo simulation to test the sustainability of portfolios with 50-50 stock bond allocation, 100 percent equity allocation, and a combination of fixed or variable annuities along with equity allocation. The authors find that using an equity portfolio with a fixed annuity component provides the highest chance of success, whereas the 50-50 equity and bond allocation offers the lowest chance of success at 5 percent rate of withdrawal. Although most previous studies have not taken into account the recent market downturn when calculating sustainable withdrawal rates, the results found using the above mentioned techniques have been remarkably similar, with most studies suggesting a sustainable withdrawal rate of 4-6 percent over a retirement life of 30-35 years.

\section{Data and Methodology}

Data used to perform the analysis was obtained from Ibbotson Stocks, Bonds, Bills, and Inflation 2009 Classic Yearbook (Ibbotson and Associates, 2009). Nominal monthly total returns were obtained for large company stocks and intermediate-term government bonds from January 1926 through December of 2008. Monthly and annual inflation rates for the same period were also recorded. Nominal monthly total returns for a constant portfolio allocation of $60 \%$ large company stocks and $40 \%$ intermediate-term government bonds were calculated.

Nineteen different hypothetical retirement distribution periods were simulated. The first distribution period started in 1990, and the nineteenth distribution period that was simulated started in 2008. In each of the nineteen distribution periods, withdrawals were made at the beginning of each month and adjusted for inflation annually. Each of the retirement distribution scenarios were modeled using actual inflation and portfolio return data, provided by Ibbotson 
and Associates (2009), through the end of 2008. The period specific simulations represent a hypothetical retiree beginning retirement that year and commencing retirement withdrawals at the start of the first month of that year. For periods beginning in 2009 , portfolio returns and inflation were simulated using bootstrap techniques. Historical monthly returns were randomly selected, with replacement, using an equal probability distribution function, to extend each of the 19 retirement distribution simulations to a period of 50 years. Each of the 19 retirement distribution period simulations is made up of 1,000 iterations. Thus, the hypothetical scenario for a retiree in 1990 extends beyond 2008, using bootstrap methods, to the year 2039, and the first nineteen years $(1990-2008)$ of portfolio returns and inflation rates for each of the 1,000 simulated iterations are identical and only vary beginning in the year 2009.

Initial withdrawal rates were set at $5 \%, 4 \%$, and $3 \%$ annually of the starting portfolio and were adjusted for inflation annually. One thousand simulated retirement distribution periods for each of the nineteen distribution periods and for each of three withdrawal rates were completed. For example, the hypothetical scenario for a retiree in 2000 consists of 1,000 simulations utilizing a 3\% withdrawal rate, 1,000 simulations using a $4 \%$ withdrawal rate, and 1,000 simulations using a $5 \%$ withdrawal rate. Successful retirement distribution scenarios were determined by whether there was a positive balance of funds in the retirement portfolio at the conclusion of 40 years. The percent of successful retirement distribution simulations was determined for each withdrawal rate and for each of the nineteen simulated distribution periods. The average duration of positive distributions was also estimated for each withdrawal rate and distribution period was also calculated.

\section{Results}

\subsection{Sustainable withdrawal rates}

The first set of columns presented in Figure 1 are the estimated success rates for retirement portfolios utilizing 5\%, $4 \%$, and $3 \%$ distribution rates but are year neutral, meaning they do not start or end in a particular year, thus all monthly portfolio returns and inflation adjustments are randomly selected. The estimated success rate over a 40 year period for a $5 \%$ withdrawal rate, using entirely simulated data is $64.9 \%$. The results (Figure 1) show that for hypothetical individuals who retired in 1990, a 5 percent withdrawal rate has a $97.4 \%$ success rate over a 40 year retirement life horizon. The estimated success rate for scenarios utilizing a lower initial withdrawal rate is even higher. Subsequently, beginning in the mid 1990s, the rate of ruin, or probability of failure, for 5 percent withdrawal rates increases substantially for the retirees. The increasing rate of failure continues through the year 2000 . Among those hypothetical retirees that experienced the market crises of 2002 and 2008 very early in their retirement, the rate of ruin increases quite dramatically. For example, a hypothetical individual retiring in the year 2000, who begins retirement distributions at $5 \%$, has an estimated success rate of $3.7 \%$, or stated oppositely, he has an estimated failure rate of $96.3 \%$. Beginning in 2001, success rates using a 5\% initial withdrawal increase, but do not increase to the level observed in the early and middle 1990s.

Hypothetical retirees utilizing a more conservative 3\% initial withdrawal are adversely affected by the market crises of 2002 and 2008; however, the success rate of such retirement portfolios has significantly less variation across the nineteen different scenarios. The lowest estimated success rate of $79.0 \%$ occurred for hypothetical individuals beginning retirement in 2000. Similarly, the rate of success for a $4 \%$ withdrawal rate remains high for hypothetical retirement distribution periods beginning in years prior to 1997, and then decreases sharply through 2000 . The success rate again improves following 2000 , however, the rate of success does not return back to the level estimated for the early 1990s.

For all three withdrawal rates, estimated success rates during the early 1990s are higher than the general success rate estimated without regard to specific years. In the late 1990s, success rates fall dramatically below the general success rate and stay below the general success rate throughout the remaining retirement distribution periods. Our results show that for individuals who have retired after the financial market downturn of 2001-2002, there is a 90 percent or higher chance of success in sustaining a withdrawal rate of 3 percent. The chance of ruin is very high and not sustainable at 5 percent withdrawal rate for the recent retirees. Among those who have retired in the first six years of the new millennium (2000-2005), the success rate is highest among the 2003 retirees, who experienced a significant market return in the first year of their retirement, while the probability of success is lowest for the 2000 retirees, who had to experience frequent and substantial market downturns (2001-2002 and 2008) very early in their retirement years.

\subsection{Retirement Life Duration}

Taking into account the prospect of increased longevity, we tested sustainable withdrawal rates over 50 year retirement period and estimated the average duration of the portfolios in Figure 2. The results show that even for a 50 year horizon, whereas 5 percent annual withdrawal rates are sustainable between 1990-1995, this withdrawal rates cannot be sustained for individuals who have retired post 1995. Also, as in the case of 40 year retirement life horizon, 4 percent withdrawal rates are sustainable between 1995 and 1997, but cannot be sustained for individuals who have retired after 1997. Beyond 1997, a 3 percent withdrawal rate is sustainable over a fifty year time horizon for individuals who have retired during 1998-2005. Among the more recent retirees (between 2000 and 2005), similar to the 40 year retirement life horizon, the chance of success is highest for the 2003 retirees, and lowest for 
the 2000 retirees.

From the results of Figure 2, we find that although 5 percent withdrawal rates are sustainable over a 35 year retirement duration for those who have retired between 1990 and 1997, this withdrawal rate cannot be sustained over a 35 year retirement life duration for 1998-2002 retirees without prematurely exhausting their portfolios. Among those who have retired after 1997, a 5 percent withdrawal rate is only sustainable for 2003 retirees, who experienced a substantial increase in market returns in the first year of their retirement. Withdrawal rate of 4 percent is however sustainable for all individuals who have retired between 1990 and 2005 over a 35 year time horizon.

Similarly, for 30 year retirement duration, the Figure 2 shows that while 5 percent withdrawal rates are sustainable for 1990-1998 retirees, this withdrawal rate cannot be sustained for those who retired at the turn of the millennium (1999-2001). 5 percent withdrawal rate is however sustainable over a 30 year period, for individuals who have retired between 2002 and 2005. As in the case of 35 year retirement duration, those retirees who have a 30 year retirement duration can sustain 4 percent withdrawal rate through out their lifetime, without exhausting their retirement portfolio prematurely.

\section{Discussion}

This paper adds to the existing body of literature on sustainable withdrawal rates by incorporating the financial market returns between 2001 and 2008 in the sustainable withdrawal rates analysis. We also address the issue of increasing longevity by calculating sustainable withdrawal rates among recent retirees over 40-50 years of retirement duration. The results are striking and the findings of this study challenge the conventional 4-6 percent withdrawal rates that financial planners typically recommend for their clients. The results show that in a typical 60-40 portfolio allocation, individuals who have retired after 1997 cannot sustain 5 percent withdrawal rates over a 35 year retirement life horizon, with the sole exception of 2003 retirees. This is primarily because the more recent retirees had to face two significant market downturns very early in their retirement. Previous studies have pointed out that due to the effect of time value of money, individuals who face significant market down turns in the early years of their retirement face the risk of exhausting their portfolio quicker than others at conventional withdrawal rates (Bengen, 1994). Conversely, the 2003 retirees are better off in this group, because they experienced substantially high market returns in the first year of their retirement unlike the 2000-2002 retirees.

The results of this study show that although 5 percent withdrawal rates are sustainable for recent retirees with a retirement horizon of 35 years or less, this withdrawal rate cannot be sustained for 1999-2001 retirees, even with reduced retirement life duration. However, the 1999-2001 retirees can still sustain 4 percent withdrawal rates over 35 year retirement life duration (with the exception of 2000 retirees) and they can sustain 4 percent withdrawal rates over a retirement duration of 30 years. One can therefore conclude from this that individuals who retired late in their lives and have a shorter retirement life expectancy (30 years or less) can sustain higher withdrawal rates even after facing two substantial market downturns very early in their retirement, whereas those who have retired early and have a longer retirement life expectancy will have to withdraw at a much lower rate in order to sustain their portfolio over life time. This might result in lowering standard of living expectations in the retirement life for the early retirees.

Estimated portfolio duration and success are important to consider when setting up a retirement distribution plan. However, one time estimations, based on general market data, can lead to irrelevant assumptions about the portfolios expected duration. Planners routinely meet with clients, typically at least annually, and update the client's profile, investment performance, and other changes pertinent to the client's financial goals. During these meetings initial estimates of portfolio sustainability should be revisited and recalculated. Particularly, financial planners' clients who began distributions in the late 1990s and early 2000s, may be overly aggressive in their distribution planning if withdrawal rates were set at $5 \%$ and not readjusted as a result of the market turmoil of the $2000 \mathrm{~s}$.

\section{Conclusion}

This paper illustrates the need to revisit sustainable withdrawal rates with clients on an annual basis, well after such distribution patterns have begun. Such reevaluations should include the portfolio performance experienced thus far by the client, and how such preexisting performance strengthens or weakens the probability of sustained distributions, given initial and current withdrawal rates. While not tested in this paper, the authors believe that modest adjustments to initial distribution plans in response to adverse market conditions may substantially improve the sustainability of the portfolio and is an area in need of additional research.

\section{References}

Ameriks, J., Veres, R. and Warshawsky, M. J. (2001). Making retirement income last a lifetime. Journal of Financial Planning, 14(12), 60-76.

Bengen, W. P. (1994). Determining withdrawal rates using historical data. Journal of Financial Planning, 7 (4), 171-180.

Bengen, W. P. (1996). Asset allocation for a lifetime. Journal of Financial Planning, 9(4), 58-67

Bengen, W. P. (1997). Conserving client portfolios during retirement. Journal of FinancialPlanning, 10 (6), 84-97. 
Cooley, P.L., Hubbard, C.M., and Waltz, D.T. (1998).Retirement savings: Choosing a retirement rate that is sustainable. Journal of the American Association of Individual Investors, 20(2), 16-21.

Cooley, P.L., Hubbard, C.M., and Waltz, D.T. (1999). Sustainable retirement rates from your retirement portfolio. Financial Counseling and Planning, 10, 39-47.

Cooley, P.L., Hubbard, C.M., and Waltz, D.T. (2003). A comparative analysis of retirement portfolio success rates: Simulation versus overlapping periods. Financial Services Review, 12(2), 115-29.

Ervin, D. M., Filer, L. H., \& Smolira, J. C. (2005). International diversification and retirement withdrawals. Mid-American Journal of Business, 20, 55-62.

Evensky, H. (2001). Heading for disaster. Financial Advisor, April 2001, 64-69.

Guyton, J.T. (2004). Decision rules and portfolio management for retirees: is the safe initial withdrawal rate too safe? Journal of Financial Planning, 17(10, 54-61.

Guyton, J.T. and Klinger, W.J. (2006) Decision rules and maximum initial withdrawal rates. Journal of Financial Planning, 19, 48-58.

Hertz, D. (1964). Risk analysis in capital investment. Harvard Business Review, 42(1).

Ho, K., Milevsky, M.A., and Robinson, C. (1994). Asset allocation, life expectancy and shortfall. Financial Services Review, 3(2), 109-126.

Hughen, J. C., Laatsch, F. E. and Klein, D. P. (2002). Withdrawal patterns and rebalancing costs for taxable portfolios, Financial Services Review 11, 341-366.

Ibbotson Associates. (2009). Stocks, bonds bills and inflation: The 2008 yearbook. Chicago, IL: Ibbotson Associates.

Laing, G.K. (2010). Impact of cognitive biases on decision making by financial planners: Sunk cost, framing and problem space. International Journal of Economics and Finance, 2(1), 11-22.

Lemoine, C., Cordell, D. \& Gustafson, A.W. (2010). Achieving sustainable retirement withdrawals: A combined equity and annuity approach. Journal of Financial Planning, 23(1), 40-47.

Lewellen, W.G. \& Long, M.S. (1976). Simulation versus single-value estimates in capital expenditure analysis. Decision Sciences, 3.

Milevsky, M.E. \& Robinson, C. (2005). A sustainable spending rate without simulation, Financial Analysts Journal, 61, 89-100.

Myers, S. (1976). Modern Developments in Financial Management. New York, NY: Praeger Publications, 457-463. Nawrocki, D. (2001). The problems with Monte Carlo simulation. Journal of Financial Planning, 11(1), 1-13.

Philippators, G.C. (1973). Financial Management: Theory and Technique. San Francisco, CA: Holden Day.

Polyak, I. (2005). New Advice to Retirees: Spend More at First, Cut Back Later. New York Times, September 25, 2005.

Pye, G. B. (1999). Sustainable real spending from pensions and investments.Journal of Financial Planning, 12(6), 80-91.

Pye, G. B. (2000). Sustainable investment withdrawals. Journal of Portfolio Management, 26, 73-83.

Rees, W. \& Sutcliffe, C. (1993). Mathematical modeling and stochastic simulation of accounting alternatives. Journal of Business, Finance \& Accounting, 20(3), 351-358.

Rubinstein, R.Y. (1981). Simulation and the Monte Carlo Method. New York, NY: John Wiley \& Sons.

Stout, R. G. (2008). Stochastic optimization of retirement portfolio asset allocations and withdrawals. Financial Services Review, 17, 1-15.

Whitaker, B.(2005). Managing Retirement, After You Really Retire. New York Times, October 16, 2005. 


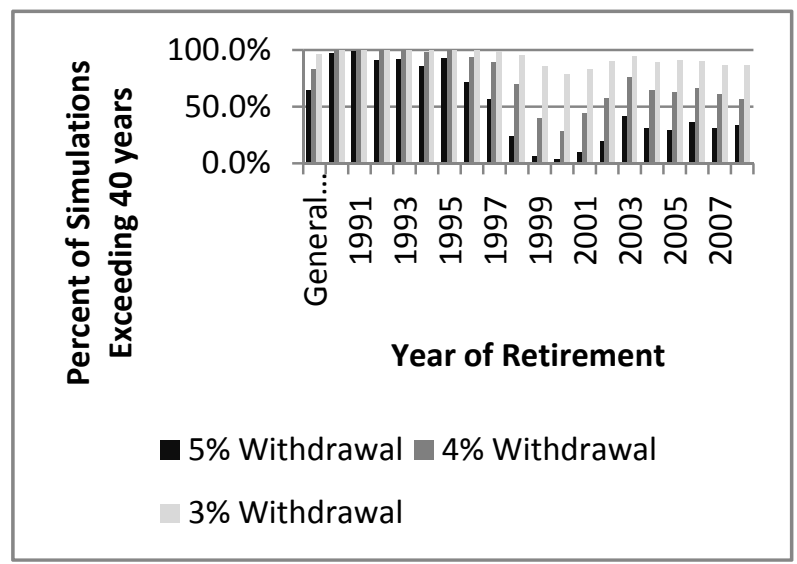

Figure 1. Portfolio safety by year of retirement

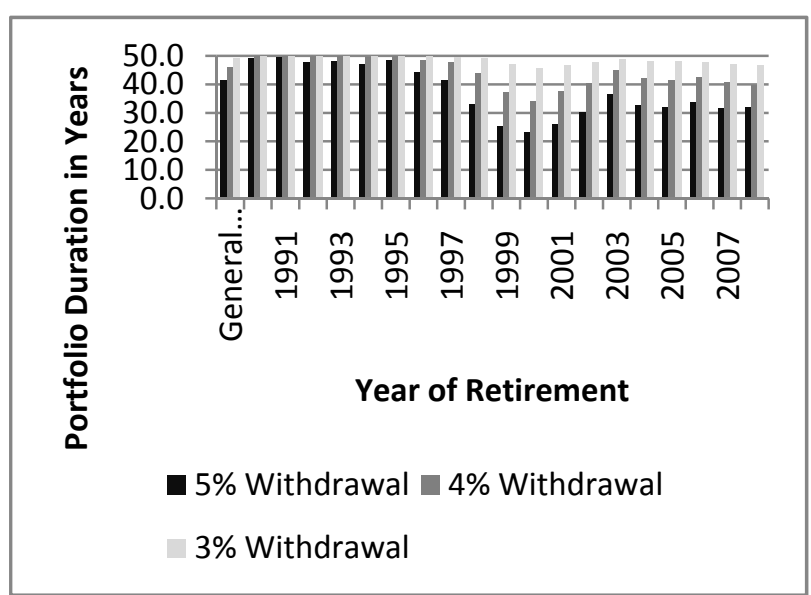

Figure 2. Portfolio Duration by Year of Retirement 